\section{Information needs of patients who undergo surgery for head and neck cancer}

\author{
By Mary Glavassevich, \\ Ann McKibbon and Sarah Thomas
}

\section{Abstract}

Individuals who undergo surgery for head and neck cancer endure significant changes in body image and lifestyle limitations; hence, they experience fear and anxiety.

A retrospective survey identified the informational needs of 32 patients who had surgery for head and neck cancer over the period July 1990 to February 199I. The survey also determined which symptoms they experienced and whether they had been informed of these before surgery.

Data from the questions revealed that most patients experienced fear, anxiety and pain. The survey indicated that most patients who had difficulties in speaking, swallowing and breathing as well as changes in appearance said they did not receive information regarding these before surgery. Preparation of patients for surgery based on informational needs is essential. The implications and recommendations for patient education will be discussed and outlined.

Head and neck cancers comprise five to six per cent of all malignancies (Dropkin, 1989; Sawyer, Bruya, 1990). These cancers involve the lip, gums, tongue, palate, mucosa of the mouth, larynx and pharynx (Mahon, 1987). The growth and invasion of cancers in these regions is generally slow (Coleman, 1986); therefore, diagnosis and treatment is sometimes delayed.

Surgical treatment aimed at completely eradicating the cancer is usually extensive. Well described in the literature are the curative surgery for head and neck cancer (Byers, Wolf, Ballantyne, 1988; Kokal et al, 1988), the reconstructive procedures (Conley, 1983; Lau, Lam, Wei, 1987; Mahon, 1987; Sullivan, Baker, Crompton, Smith-Wheeler, 1989) and the nursing care (Feinstein, 1987; Mahon, 1987; Sawyer, Bruya, 1990; Rodzwic, Donnard, 1986; Smith Schwartz, Yuska, 1989). Heightened emphasis is being placed on the challenging surgical nursing management of individuals with head and neck cancer because surgery often results in lifestyle limitations.

Individuals may not be adequately prepared to cope with surgery and the aftermath, in particular changes in appearance and function. Just how well individuals cope with these changes could depend on the extent to which their informational needs are met. The assessment of the patients' willingness to accept the resultant functional disabilities and cosmetic deformities needs to be part of the pre-operative education (Brown, Cowdeu, Gates, Davis, Richmond, 1986).

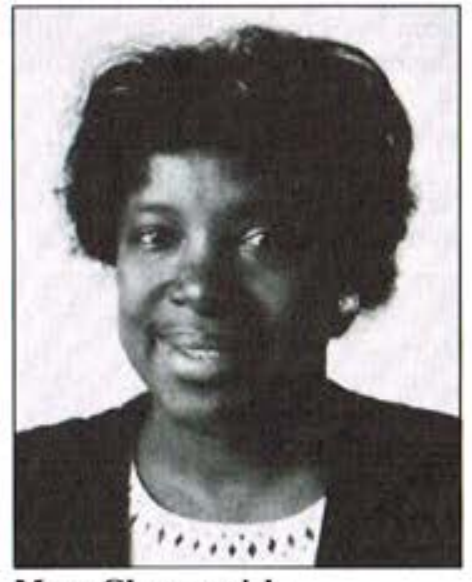

Mary Glavassevich
Some patients experience the pain of headache rather than incisional pain (Rodzwic, Donnard, 1986; Sawyer, Bruya, 1990). In a recent study of patients with head and neck cancer, Watt-Watson, Graydon, Vincent, Glavassevich and Gilbert (unpublished 1993) reported that patients described the pain as aching, nagging, tender, miserable and throbbing. However, the pain is thought to be less than for abdominal surgery (Smith Schwartz, Yuska, 1989). Other symptoms experienced include difficulties in breathing, swallowing and speech, and these are all well documented in the literature (Feinstein, 1987; Rodzwic, Donnard, 1986; McQuarrie, 1992).

Nurses are in a position to make a difference to the overall management and surgical outcome for individuals undergoing head and neck surgery by providing adequate information necessary to reduce the anxiety and fear experienced by these individuals. According to Sawyer and Bruya (1990), and Lockhart, Troff and Artim (1992), potential fear and anxiety are related to the impending surgery. Assessment of the individual's knowledge, with planned education pre-operatively and post-operatively, may reduce fear and anxiety in this group of patients (Coleman, 1986; Dropkin, 1989; Sawyer, Bruya, 1990). Anxiety has been identified as influencing the patients' perception of what information they had received prior to surgery (Cupples, 1990).

Specific education for the population of head and neck patients, based on informational needs, has not been addressed. Coleman (1986) emphasized the importance of pre-operative education including provision for adequate support structures by medical personnel and family in the overall management of patients undergoing head and neck surgery. Feinstein (1987), Jacobs and Marunick (1988) found that pre-operative education enhances the success of the transition from the hospital to home and the ultimate rehabilitation of these patients. Education for patients and families should continue throughout hospitalization and involve considerable follow-up in the post-operative phase. Nurses are responsible for providing support for patients and their families undergoing head and neck surgery through the provision of extensive pre-operative teaching (Mahon, 1987; Smith Schwartz, Yuska, 1989).

Several studies have focused on the effect of teaching on reducing complications (Coleman, 1986; Conley, 1983; Mahon, 1987; Rodzwic,

\section{BESOINS EN INFORMATION DES PATIENTS QUI SUBISSENT UNE OPÉRATION POUR UN CANCER DE LA TÊTE ET DU COU}

\section{ABRÉGÉ}

Les personnes qui subissent des opérations pour un cancer de la tête et du cou doivent faire face à d'importants changements au niveau de l'image de soi et du mode de vie, ce qui fait qu'elles ressentent peur et anxiété.

Une enquête rétrospective a défini les besoins en information de 32 patients qui avaient subi des opérations pour un cancer de la tête et du cou entre juillet 1990 et février 1991. L'enquête a aussi permis de déterminer les symptômes que ces personnes avaient eus et si elles en avaient été informées avant l'opération.

Les résultats nous apprennent que la plupart des patients ont connu la peur et l'anxiété ainsi que la douleur. Ils révèlent aussi que la plupart des patients qui éprouvaient du mal à parler, à avaler et à respirer et qui subissaient des changements au niveau de leur apparence n'avaient reçu aucune information à ce sujet avant l'opération. Il est vital de bien préparer les patients aux opérations chirurgicales en se basant sur leurs besoins en information. L'article présente et souligne les implications que tout cela a pour l'enseignement aux patients et offre des recommandations.

Mary Glavassevich, RN, SCM, BA, is nursing unit director, surgery, Ann McKibbon, RN, BScN, is nursing unit director and Sarah Thomas, RN, BA, is clinical educator, all at Sunnybrook Health Sciences Centre, Toronto, Ontario. 
Donnard, 1986). However, patients' perception of their educational needs and their experiences which would be valued in the care of the head and neck surgical patients have not been explored. Hence, a retrospective study was concluded, using a questionnaire specifically designed to explore informational needs of individuals who undergo surgery for head and neck cancers.

\section{Methodology}

Forty-five patients from a large teaching hospital who had surgery for head and neck cancer from July 1990 to February 1991 were sent written explanations of the survey and were asked to complete and return the enclosed questionnaire.

The patients who were surveyed had undergone the following procedures:

Neck dissection combined with oral mandibular reconstruction 27

Thyroidectomy

Laryngectomy

Parotidectomy

Orbit reconstruction

Thirty-two completed questionnaires were returned. Responses were received from 21 men and 11 women. The mean age for the patients was 59.5 years.

\section{Questionnaire}

The questionnaire was developed for this study to collect demographics and informational needs of head and neck cancer patients during hospitalization and after discharge. The questionnaire consisted of 11 questions, with four questions designed to be open-ended. Questions focused on what information was given, by whom, and when it was given. Patients were asked to identify the information that was most helpful and least helpful. One question specifically asked patients to identify the information which should be given to other patients undergoing this surgery. From clinical experience and the literature, the most common symptoms were predetermined by the investigators. Patients indicated on the questionnaire which symptoms they had experienced before and after surgery. Patients were also asked to indicate if they had been informed of these symptoms prior to their surgery.

\section{Analysis}

The responses to the questions were itemized by each of the investigators and then categorized by predominant themes. The following themes were identified:

a) the need for information

b) the source, timing and sequencing of information

c) the presentation of information

d) what they would tell others

e) the symptoms they experienced

f) their attitude toward surgery

\section{Results}

\section{Need for information}

The reason for the surgery and also the nature and extent of the surgery were explained to all 32 respondents. All respondents indicated more information was needed before surgery regarding the course of their illness and events that would occur. For example, one respondent indicated that he was not prepared for nausea or dreams experienced in the recovery room. Complications from and reasons for the extent of surgery were also a concern. Two patients in the study expressed their feelings following tracheostomy as frightening, a feeling as if their throats were being slashed. Respondents identified what to expect after surgery and the long-term prognosis as information that is most helpful and necessary to know. Prior to surgery, the possibility of additional radiotherapy treatment being required should be discussed. Most respondents stated they were not prepared for some outcomes experienced following the surgery such as neck stiffness, loss of sensation in the neck area, scarring and fistulas. When asked what they would tell other patients, some themes became apparent. These included: The prolonged recovery process, confidence in the health team, the pain experience, and realization that surgery was the only option.

\section{Source of information}

All respondents received information from their physician. As well, 10 respondents received information from the nursing staff, and one respondent indicated the physiotherapist provided some information.

\section{Timing and sequence of information}

Respondents were asked if they had received information before or after surgery. Thirty had received information before surgery and five had been given information after surgery. Respondents were also asked specific questions regarding the kind of information they had received before surgery. Before the surgery, 24 had received information concerning the expected post-operative course. Twenty-seven were told how they would be cared for following their surgery which they felt prepared them for the surgical experience. The long-term effects of surgery were described to 23 respondents. Twenty-eight were told of possible complications.

\section{Presentation of information}

No content was identified as least helpful. Responses regarding presentation of information produced a variety of answers. Three responded that the information was too simple and five responded that the information was too technical. Five respondents indicated that the information was given too quickly and five indicated that it was given too slowly. Thirty respondents signified that they were given enough time to ask questions. Twenty-nine respondents reported that they were comfortable asking questions. Written questions had been prepared for their physicians by 12 respondents.

\section{Symptoms experienced}

Respondents were specifically asked to indicate what symptoms they had experienced before and after surgery. They were also asked to indicate if they had been informed of these effects prior to surgery. Their responses were varied as indicated in Figure One.

In most cases, feelings of fear and anxiety were not addressed prior to surgery. Of the 15 respondents who indicated they were fearful prior to surgery, only four reported that fear was addressed prior to surgery. Pain was experienced by 15 respondents after surgery; however, only eight were informed of pain prior to surgery. Although some pain was expected with surgery, the respondents indicated that they experienced more discomfort than pain and less than anticipated. Seven respondents indicated that they had experienced difficulty breathing post-operatively, yet only three respondents were prepared for this. Difficulty in swallowing was experienced by 15 respondents; however, only eight were told that this would occur. After the surgery, 17 respondents signified that they had difficulty in speaking and 11 had been informed of this possibility. Eighteen respondents experienced changes in appearance and 13 had been informed before surgery.

\section{Attitude toward the surgery}

Nineteen responded positively toward having the surgery, viewing the surgery as the only option. They expressed confidence in the doctors, nursing team, and satisfaction in the overall success of the surgery.

Figure One: Number of patients reporting symptoms associated with head and neck surgery

$\begin{array}{lll}\begin{array}{l}\text { Before } \\ \text { surgery }\end{array} & \begin{array}{l}\text { After } \\ \text { surgery }\end{array} & \begin{array}{l}\text { Informed of symptoms } \\ \text { before surgery }\end{array}\end{array}$

\begin{tabular}{|lrrr|} 
Fear & 15 & 5 & 4 \\
Anxiety & 16 & 9 & 7 \\
Pain & 6 & 15 & 8 \\
Difficulty breathing & 3 & 7 & 3 \\
Difficulty swallowing & 5 & 15 & 8 \\
Difficulty speaking & 4 & 17 & 11 \\
Changes in appearance & 4 & 18 & 13 \\
\hline
\end{tabular}




\section{Discussion}

The results of the survey indicate that even though patients were given some information, they felt inadequately prepared for surgery and the post-operative course. Some patients did not feel well-informed about the usual problems associated with their surgery. Patients undergoing head and neck surgery not only struggle with the diagnosis of cancer, but they also have to cope with pain, impending disfigurement and alterations in speech and swallowing often associated with the surgery. It is known that physical appearance may be altered as a result of the surgery. This can further increase the anxiety level of these individuals as appearance is highly valued in society (Dropkin, 1989; McQuarrie, 1992).

Anxieties relating to these issues could be reduced through provision of information to these patients. As informational needs are met, it is anticipated that the patients' fear and anxiety regarding surgery and its effects will decrease (Coleman, 1986; Dropkin, 1989; Sawyer, Bruya, 1990). Considering the serious consequences of anxiety, it is imperative that information be provided to the patient to decrease fear. These patients are said to experience stressors that go beyond those which occur with the usual surgical patients (Bronheim, Strain, Biller, 1991). Anxiety may persist well into the post-operative phase of the illness experience.

Most patients in the study indicated that the information given pre-operatively should emphasize that the process of recovery can be long. They also indicated that patients need to be aware of the possibility of paraesthesia to the skin over the operative site and neck stiffness. Additional information identified as important for other patients to know included difficulties in speaking, swallowing and breathing. It was a surprise to discover that pain reported by patients was less than

\section{References}

Bronheim, H., Strain, J.J., Biller, H.F. (1991). Psychiatric aspects of head and neck surgery, Part 1: New surgical techniques and psychiatric consequences. General Hospital Psychiatry, 13, 165-176.

Brown, J.G., Cowdeu, W., Gates, E., Davis, E., Richmond, T.S. (1986). Nursing management of the patient with total en bloc resection of the temporal bone. Journal of Neuroscience Nursing, 18(6), 349-353.

Byers, R.M., Wolf, P.F., Ballantyne, A.J. (1988). Rationale for elective modified neck dissection. Head and Neck Surgery, 10(3), 160-167.

Coleman, J.J. (1986). Complications in head and neck surgery. Surgical Clinics of North America, 66(1), 149-167.

Conley, J. (1983). Trends in minimizing deformity in head and neck resections. The Journal of Laryngology and Otology, 97, 1047-1052.

Cupples, S. (1990). Effects of preadmission teaching on knowledge and postoperative recovery of coronary artery bypass graft patients. Key Aspects of Recovery: Improving Nutrition, Rest and Mobility. Edited by Funk, S., Tornquist, E., Champagne, M., Archer Copp, L., Weise, R. Springer Publishing Co., 299-307.

Dropkin, M.J. (1989). Coping with disfigurement and dysfunction after head and neck cancer surgery: A conceptual framework. Seminars in Oncology Nursing, 5(3), 213-219.

Feinstein, D. (1987). What to teach the patient who's had a total laryngectomy, RN, 50, 53-57.

Glavassevich, M., Thomas, S., Galloway, S.C. (1989). Informational needs of patients who undergo excision of an acoustic neuroma. AXON, 2(1), 17-19.

Glavassevich, M., Thomas, S., Galloway, S.C. (1991). An educational program to improve the quality of life for individuals with acoustic neuroma. Journal of Neuroscience Nursing, 23(4), 231-234.

Jacobs, J.R., Marunick, M.T. (1988). Surgical considerations in maxillofacial prosthetic rehabilitation of the maxillectomy speaking patient. Journal of the Surgical Oncology, 37(1), 29-32. expected considering the extent of their surgery.

Addressing patients' informational needs early pre-operatively may reduce anxiety. Patient education is an ongoing process that needs to be initiated prior to surgery. Work done by Glavassevich, Thomas and Galloway (1989) indicated that patients admitted for removal of an acoustic neuroma could have benefitted from more information delivered earlier. Their study indicated that the patients needed to have a picture or cognitive map of the events they would experience. This process allows the patients to mentally rehearse the event (McHugh, Christman, Johnson, 1982).

The role of the nurse in identifying and meeting the informational needs of the head and neck cancer patients is important to the overall management of their care. The nurse is in a unique situation to identify informational needs and effectively prepare patients for surgery and the aftermath.

\section{Implications for practice and research}

It would be in the interest of patient care that a formal education structure be developed to ensure that patient teaching take place. Glavassevich, Thomas and Galloway (1991) designed an educational program for a specific patient population based on the identified informational needs of patients. It is anticipated that education of nurses concerning the illness experience of head and neck cancer could improve the quality and quantity of information given (Glavassevich, et al, 1989). Formalized teaching content would provide some consistency for staff as well as patients. It is also essential that timing and presentation be tailored to the individual needs and learning styles of the patient. The learning needs identified in the study could serve as the framework for the educational program. Once the educational program is in place, a repeat survey should be conducted.

Kokal, W.A., Niefeld, J.P., Eisert, D., Lipsett, J.A., Lawrence, W. Jr., Beatty, J.D., Parker, G.A., Pezner, R.D., Riihimaki, D.U., Terz, J.J. (1988). Post-operative radiation as adjuvant treatment for carcinoma of the oral cavity, larynx and pharynx: preliminary report of a prospective randomized trial. Journal of Surgical Oncology, 38(2), 71-76.

Lau, W.F., Lam, K.H., Wei, W.I. (1987). Reconstruction of hypopharyngeal defects in cancer surgery: Do we have a choice? The American Journal of Surgery, 154(4), 374-380.

Lockhart, J.S., Troff, J.L., Artim, L.S. (1992). Total laryngectomy and radical neck dissection. AORN Journal, 55(2), 458-479.

Mahon, S.M. (1987). Nursing interventions for the patient with a myocutaneous flap. Cancer Nursing, 10(1), 21-31.

McHugh, N., Christman, N., Johnson, J. (1982). Preparatory information: What helps and why. American Journal of Nursing, 8, 180.

McQuarrie, D.G. (1992). Head and Neck Cancer. An overview for the perioperative nurse. AORN Journal, 56(1).

Rodzwic, D., Donnard, J. (1986). The use of myocutaneous flaps in reconstructive surgery for head and neck cancer: Guidelines for nursing care. Oncology Nursing Forum, 13(3), 29-34.

Sawyer, D.L., Bruya, M.A. (1990). Care of the patient having radical neck surgery or permanent laryngostomy: A nursing diagnostic approach. Focus on Critical Care, 27(2), 166-173.

Smith Schwartz, S., Yuska, C.M. (1989). Common patient care issues following surgery for head and neck cancer. Seminars in Oncology Nursing, 5(3), 191-194.

Sullivan, M.J., Baker, S.R., Cromptom, R., Smith-Wheelock, M. (1989). Free scapular osteocutaneous flap for mandibular reconstruction. Archives of Otolaryngology Head and Neck Surgery, 155(11), 1334-1340.

Watt-Watson, J., Graydon, J., Vincent, L., Glavassevich, M., Gilbert, R. Pain, fatigue and mood in head and neck cancer patients. (Unpublished 1993). 